\title{
Is Endoscopic Lung Volume Reduction Able to Reverse Pulmonary Hypertension in Patients with Severe Emphysema?
}

\author{
António Bugalho \\ Intervention Pulmonology Unit, Hospital Beatriz Ângelo, Loures, and Chronic Diseases Research Center (CEDOC), \\ Faculdade de Ciências Médicas, Universidade Nova de Lisboa, Lisbon, Portugal
}

Chronic obstructive pulmonary disease (COPD) has a growing burden throughout the world. Fortunately, most patients have mild to moderate disease which is controlled with a combined approach that includes smoking cessation, bronchodilators, inhaled corticosteroids and pulmonary rehabilitation, according to international guidelines [1].

In a subgroup of COPD patients with predominant parenchymal destruction and severe chronic airflow limitation there is frequently hyperinflation and abnormal lung mechanics, resulting in increasing dyspnea, reduced exercise capacity, poor quality of life and increase mortality. Current knowledge shows that COPD, and particularly the emphysema phenotype, has implications beyond the respiratory system with a clear deleterious effect on a cardiovascular level. Pulmonary hypertension (PH) can occur as part of the natural history of COPD and is estimated to affect at least $20 \%$ of patients with advanced disease and chronic respiratory failure. Most cases have a mild to moderate and slowly progressive increase in mean pulmonary artery pressure (PAP) at rest (PAP $\geq 25$ and $<40$ $\mathrm{mm} \mathrm{Hg}$, rate of $+0.4 \mathrm{~mm} \mathrm{Hg} /$ year), still it may be further abnormal during acute exacerbations, exercise and sleep $[2,3]$.

COPD-related $\mathrm{PH}$ pathophysiology is typically linked to progressive airflow obstruction, persistent alveolar hypoxia and hypoxemia. This fact made it being classified (c) 2014 S. Karger AG, Basel

0025-7931/14/0891-0012\$39.50/0 within group 3 - PH due to lung diseases and/or hypoxia - in the 2013 NICE classification [4]. In these patients, $\mathrm{PH}$ treatment is usually limited to long-term oxygen therapy (LTOT) and if it is not optimized there is potential for $\mathrm{PH}$ to get worse. Systemic drugs have proved their value in idiopathic $\mathrm{PH}$; however, a real benefit has not yet been confirmed in COPD patients and with some therapies, there was even a deleterious effect on gas exchange.

Although the most studied factor relates to the response of pulmonary vascular structures to alveolar hypoxia, with increased pulmonary vascular resistance and arterial pressure, other mechanisms have been implicated. They include chronic inflammation with remodeling of the pulmonary arteries and capillaries, endothelial dysfunction, local vascular thrombosis and loss of the pulmonary vessels [5]. Multiple studies established, more than 20 years ago, that air trapping and lung hyperinflation have also an important role since they raise intrathoracic pressure and can cause an increase in pulmonary artery wedge pressure, affect heart-filling pressures, and in time contribute to the development of right heart failure in emphysema patients. Since several factors are responsible for COPD-related PH it makes sense to attempt different therapeutic options.

Moreover, in COPD patients, the correct diagnosis of $\mathrm{PH}$ although commonly promoted has limited therapeutic impact except in candidates for pulmonary transplan-
Dr. António Bugalho

Intervention Pulmonology Unit, Hospital Beatriz Ângelo Avenida Carlos Teixeira 3 PT-2674-514 Loures (Portugal)

E-Mail antonio.bugalho@hbeatrizangelo.pt 
tation or lung volume reduction surgery (LVRS). It is important to mention that $\mathrm{PH} \geq 35 \mathrm{~mm} \mathrm{Hg}$ is a relative contraindication to LVRS since previous trials have shown conflicting results regarding vascular hemodynamics in emphysema patients after LVRS. A reduction in lung hyperinflation and an improvement in gas exchange may reduce $\mathrm{PAP}$, but on the other hand resection of pulmonary tissue and consequently lung vessels can generate an adverse increase in $\mathrm{PH}$. Endoscopic lung volume reduction (ELVR) using endobronchial unidirectional valves is a recent but progressively established intervention aimed to reduce hyperinflation in patients with advanced emphysema. Data from a recent meta-analysis shows that ELVR improves lung function and exercise capacity and can safely be performed in patients with comorbidities that preclude LVRS [6].

In the current issue of Respiration, Eberhardt et al. [7] report the findings of a pilot study examining the feasibility and efficacy of ELVR with Zephyr valves in patients with severe heterogeneous emphysema and proven $\mathrm{PH}$. Six patients were submitted to a full workup according to $\mathrm{PH}$ diagnostic recommendations, including right heart catheterization, at baseline and 90 days after unilateral valve deployment. The procedure was feasible in $100 \%$ of cases and there was clinical, radiological and hemodynamic improvement in $83 \%$ of patients. There was an overall decrease in mean PAP $(-2.5 \pm 3.5 \mathrm{~mm} \mathrm{Hg})$ and in pulmonary artery wedge pressure $(-4.3 \pm 8.3 \mathrm{~mm} \mathrm{Hg})$ with an increase in right ventricular function, 6-min walking distance $(+58.8 \pm 98.8 \mathrm{~m})$ and forced expiratory volume in $1 \mathrm{~s}\left(\mathrm{FEV}_{1},+0.2 \pm 0.3\right.$ liters). Patient-reported outcomes, such as quality of life and dyspnea, had an improvement from baseline.

It should be emphasized that the ELVR therapeutic response was highly variable among these patients with emphysema and $\mathrm{PH}$. In 2 cases there was minimal or absent volume reduction of the treated pulmonary lobe; 4 of 6 patients had a negligible improvement in $\mathrm{FEV}_{1} ; 6$-min walk distance increased significantly only in 2 patients. In contrast, the hemodynamic results were more consistent. Usually, COPD therapeutic studies rely on specific endpoints such as $\mathrm{FEV}_{1}, 6$-min walk test and exacerbations. The recognition of multifactorial pathological changes with systemic effects may explain why some parameters, such as lung function, correlated poorly with other outcomes and alert for the need of comprehensive indicators to assess treatment efficacy.

One of the strong features of the present study was the correct measurement of pulmonary vascular hemodynamics through right heart catheterization as transthorac- ic Doppler echocardiography alone is not accurate in the emphysematous patient. In 2003, Arcasoy et al. [8] used this noninvasive method to evaluate 374 patients and technical difficulties were described in $56 \%$ due to air interposition and in $52 \%$ cases pressure estimation was $>10 \mathrm{~mm}$ $\mathrm{Hg}$ different from the gold standard. Nevertheless, right heart catheterization is an invasive procedure and is not routinely advocated for severe COPD patients as part of the diagnostic or therapeutic algorithm. The fact that it can be performed only in selected cases may perhaps explain the inclusion of merely 6 patients during a 3-year period.

The current study shows that flattening of the diaphragm and hyperinflation may attenuate venous return, lead to a decrease in resting cardiac output and compress alveolar vessels generating an increase in mean PAP. This might be partially reversible by ELVR possibly due to an optimization of cardiac function and recruitment of previously nonperfused vessels. Pulmonary arteries supplying the upper lobes are smaller and fewer in number than those in the lower lobes. Since 4 patients were treated to the upper lobe and 2 to the lower lobe we cannot exclude that regional pulmonary vascular bed differences may be responsible for the outcome heterogeneity [9].

As previously stated, in patients with resting hypoxemia and stable COPD, LTOT is a recommended therapeutic modality because it stabilizes and sometimes reverses the progression of $\mathrm{PH}$, improving survival. Preceding prospective trials reported LTOT to be able to mildly reduce mean PAP in COPD patients ( -2.8 to $3 \mathrm{~mm} \mathrm{Hg}$ ) $[10,11]$, diminishing the frequency of exacerbations and increasing exercise capacity [12]. The fact that other mechanisms, apart from hypoxia-induced vasoconstriction, are implicated in the pathophysiology of $\mathrm{PH}$ may explain why LTOT alone fails not only to normalize $\mathrm{PH}$ but also to maintain a sustained long-term beneficial effect. In the present work, ELVR decreased mean PAP with a degree similar to LTOT $(-2.5 \pm 3.5 \mathrm{~mm} \mathrm{Hg})$.

According to this and earlier studies, ELVR has proven to be quite safe, although in 1 case there was a serious procedure-related morbidity (pneumothorax).

In future trials it is essential to consistently identify clusters of patients with $\mathrm{PH}$-related emphysema that are responders and distinguish the ones at high risk for ELVR. Despite the promising preliminary results of the current study, demonstrating the feasibility of ELVR in COPDassociated $\mathrm{PH}$, further and larger trials are needed to confirm its clinical efficacy and investigate potential treatment options for long-term improvement in emphysema patients with mild to moderate $\mathrm{PH}$. 


\section{References}

1 Vestbo J, Hurd SS, Agusti AG, Jones PW, Vogelmeier C, Anzueto A, Barnes PJ, Fabbri LM, Martinez FJ, Nishimura M, Stockley RA, Sin DD, Rodriguez-Roisin R: Global strategy for the diagnosis, management, and prevention of chronic obstructive pulmonary disease: GOLD executive summary. Am J Respir Crit Care Med 2013;187:347-365.

-2 Minai OA, Chaouat A, Adnot S: Pulmonary hypertension in COPD: epidemiology, significance, and management: pulmonary vascular disease: the global perspective. Chest 2010; 137(suppl 6):39S-51S.

$\checkmark 3$ Kessler R, Faller M, Weitzenblum E, Chaouat A, Aykut A, Ducoloné A, Ehrhart M, OswaldMammosser M: 'Natural history' of pulmonary hypertension in a series of 131 patients with chronic obstructive lung disease. Am J Respir Crit Care Med 2001;164:219-224.

4 Simonneau G, Gatzoulis MA, Adatia I, Celermajer D, Denton C, Ghofrani A, Gomez Sanchez MA, Krishna Kumar R, Landzberg M, Machado RF, Olschewski H, Robbins IM, Souza R: Updated clinical classification of pulmonary hypertension. J Am Coll Cardiol 2013;62(suppl 25):D34-D41.
5 Matsuoka S, Washko GR, Yamashiro T, Estepar RS, Diaz A, Silverman EK, Hoffman E, Fessler HE, Criner GJ, Marchetti N, Scharf SM, Martinez FJ, Reilly JJ, Hatabu H; National Emphysema Treatment Trial Research Group: Pulmonary hypertension and computed tomography measurement of small pulmonary vessels in severe emphysema. Am J Respir Crit Care Med 2010;181:218-225.

6 Iftikhar IH, McGuire FR, Musani AI: Efficacy of bronchoscopic lung volume reduction: a meta-analysis. Int J Chron Obstruct Pulmon Dis 2014;9:481-491.

-7 Eberhardt R, Gerovasili V, Kontogianni K, Gompelmann D, Ehlken N, Herth FJF, Grünig E, Nagel C: Endoscopic lung volume reduction with endobronchial valves in patients with severe emphysema and established pulmonary hypertension. Respiration 2015;89:41-48.
8 Arcasoy SM, Christie JD, Ferrari VA, Sutton MS, Zisman DA, Blumenthal NP, Pochettino A, Kotloff RM: Echocardiographic assessment of pulmonary hypertension in patients with advanced lung disease. Am J Respir Crit Care Med 2003;167:735-740.

$\checkmark 9$ Wrobel JP, McLean CA, Thompson BR, Stuart-Andrews CR, Paul E, Snell GI, Williams TJ: Pulmonary arterial remodeling in chronic obstructive pulmonary disease is lobe dependent. Pulm Circ 2013;3:665-674.

10 Long term domiciliary oxygen therapy in chronic hypoxic cor pulmonale complicating chronic bronchitis and emphysema. Report of the Medical Research Council Working Party. Lancet 1981;1:681-686.

11 Timms RM, Khaja FU, Williams GW: Hemodynamic response to oxygen therapy in chronic obstructive pulmonary disease. Ann Intern Med 1985;102:29-36.

12 Kim V, Benditt JO, Wise RA, Sharafkhaneh A: Oxygen therapy in chronic obstructive pulmonary disease. Proc Am Thorac Soc 2008;5: 513-518. 